\title{
A GUIDE IN THE USE OF EXISTING MAINTENANCE AND RELIABILITY THEORIES TO ENHANCE EQUIPMENT RELIABILITY AND AVAILABILITY IN CARIBBEAN INDUSTRIES
}

\author{
Kishore Jhagroo \\ Faculty of Engineering, the University of the West Indies, Trinidad \\ Email: Kishore.Jhagroo@sta.uwi.edu
}

\begin{abstract}
In order to improve the Equipment Reliability and Availability in the Industries in the Caribbean this paper discusses the use of existing Maintenance and Reliability theories in the areas of condition monitoring techniques, root cause analyses, quality systems, Computerized Maintenance Management Systems (CMMS), Planning and Scheduling, Reliability Centered Maintenance (RCM), Total Productive Maintenance (TPM), the Ishikawa Diagram in addition to introducing a guide to facilitate their application. It describes the management accounting system, driven by leading and lagging Key Performance Indicators (KPI's), which ensure sustainability in the implementation of the improvement recommendations in the maintenance and reliability systems in these industries. Emphasis is placed on the need for Engineers and other professionals in the industry to play key roles in deciding when and for how long equipment shall be run and subsequently taken out of service. This can only be achieved by "placing their shoulders to the wheel" and working with passion towards their focused goals. They need to celebrate and learn from their successes and be innovative and critical thinkers to efficiently and effectively surmount any barriers in their way.
\end{abstract}

Keywords: Maintenance, Reliability, Root Cause Analysis, Planning and Scheduling, KPIs.

https://doi.org/10.47412/SYFU5666

\section{Introduction}

Review of the graduates' capstone project reports and dissertations from the students of the MSc Engineering Asset Management (EAM) programme in the Department of Mechanical and Manufacturing Engineering (DMME), since the year 2010, revealed that approximately 80\% of these studies are based on the improvement of the existing maintenance and reliability systems in the industries in Trinidad and Tobago (T\&T) and the wider Caribbean Region. This paper aims to provide guidelines to young Engineering and other professionals who are given the responsibility to improve the Maintenance and Reliability systems in any industry in the Caribbean. The following shall be covered: 
- The identification of the key areas and systems in these industries which impact on Asset Integrity.

- The presentation of the Total Improvement Model, the Change Management Model, the Reliability Improvement Model, the Modified P-F Curve Model, the CMMS Repair Strategy Model and the Strategy Improvement Model.

- The demonstration of how these models utilize the existing reliability theories to interface with the key areas mentioned above and thus be used to gain the improvements required.

- A system which can be used to audit the compliance to implementation of recommendations and the actions which can be taken to close any gaps identified.

\section{Some Key Areas in the Industries Which Impact on Asset Integrity}

The following are some of the key areas which impact on Asset Integrity:

- Analysis of the failures and the development of suitable recommendations to prevent these failures in the future.

- The implementation and quality control of the recommendations derived from the failure investigations.

- The accurate and timely recording of all of the data derived from the items listed above.

- The planning, scheduling and feedback information from all activities involved in the life cycle of the equipment.

- The auditing of the performance trends to determine compliance to the requirements, the identification and the closing of all gaps.

Benchmarking studies can provide the acceptable level of performance in each of these areas and improvements are required when these levels of performance are not achieved.

\subsection{The Total Improvement Model (Model 1) and Change Management Model (Model 2)}

The Total Improvement Model 1 identifies the stages through which and industry must progress with respect to the development of their productivity and the use of their Maintenance and Reliability systems. The terms Unconscious Incompetence to Unconscious Competence were first used in 1970 by the Gordon Training International and its employee Noel Burch. These terms shall be used to fully describe the stages of maturity of the industries. The industries that perform without any benchmarking can function in a state where they are considered to be "Unconsciously Incompetent-(UI)". They are not aware of where they are relative to their competitors and although they may be profitable, are not aware as to how much better they can be. They only deal with their internal standards and systems and their progress is based only on internal influences, comparable to level 1, Confusion [7].

Benchmarking, positions these industries into a state of being "Consciously Incompetent (CI)". They are now aware of their deficiencies, comparable to Level 2, Awareness [7]. They are aware of where they are and where they would like to be in the future. They now have to make a decision if they want to improve their performance to stay competitive. This can only be achieved by analysing their deficiencies and developing strategies to close the gaps identified. Discussions with the EAM students indicate that generally the areas of concern are the deficiencies in the use of the existing system, mainly in the way work is performed. Individuals are just not doing what they are 
supposed to do, as outline by the industry's requirements e.g. the processes, procedures, quality control and audit requirements. The model refers to this increase in the effort required, as the "Physical Hump", since individuals just need to follow the requirements of the system without any great addition of technical inputs. This is one of the greatest challenges faced by most industries in this change process. The change agents, generally the Reliability and Maintenance engineers need the support of the senior management team to be able to activate this change [5][7].

There is a need to increase their effort e.g. resources, training, communication and finances in order to cross this "First Hump" It is indeed an "uphill battle" and can only be achieved by the "change agents" controlling the turmoil in the system. The Change Management Model 2 explains the process which can be used. In the "UI" stage the turmoil in the system is very high and can be compared to the "Storming" stage in the development of a Team. While this turmoil is being controlled, the Engineers need to "be ahead of the game" and as such be able to lead the direction of the change. In order to get this done there is a need for strategic, root cause and critical thinking which must result in innovative, new ideas and the discipline to follow the existing requirements [2][5]

Note: It is very difficult to eliminate the turmoil completely since the normal characteristics of the Trinidad and Tobago workforce, in the present environment, prevents this from happening. The key to success is the need for the change agents to be focused, with the assistance of the management's team, on the changes required and the strategic goals set for the industries.

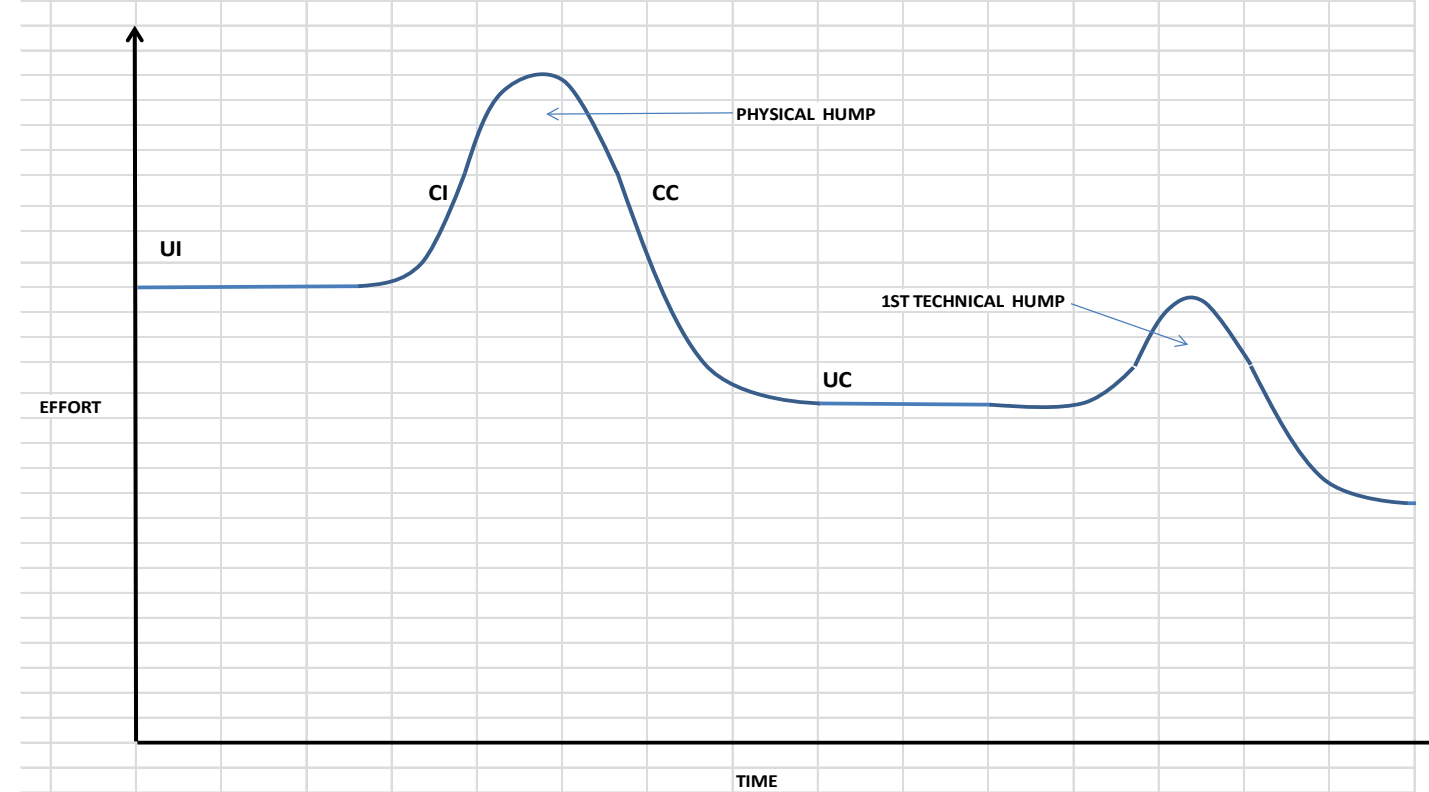

Figure 1. The Total Improvement Model 1 (Source: Jhagroo, 2014 and Gordon Training International employee Noel Burch, 1970) 


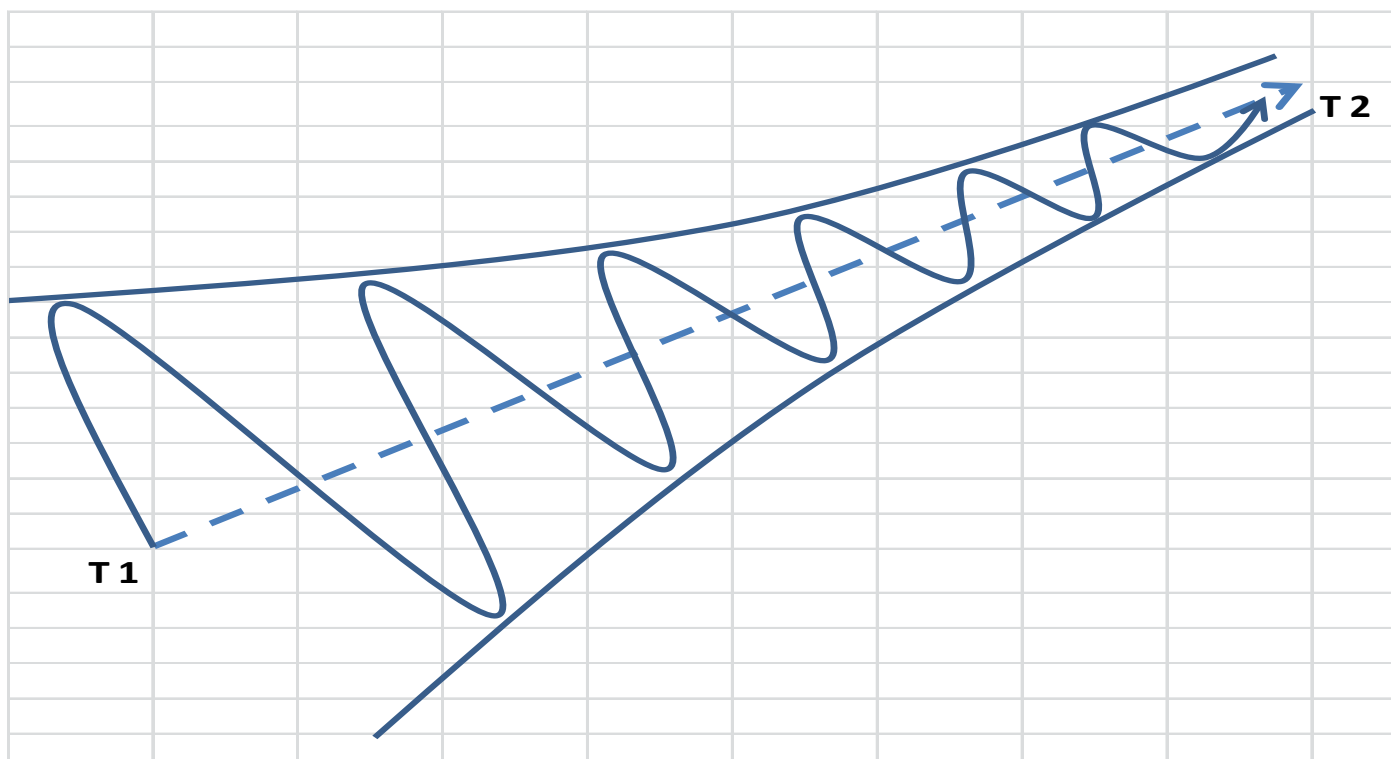

Figure 2. The Change Management Model 2 (Source: Jhagroo, 2014)

The major issues to be considered in this "First hump" are the identification of the existing requirements, the determination of how work is performed with the gaps existing relative to the existing requirements and the determination of the methods to close the gaps. Leadership, Training and Mentoring are all key strategies which can be utilized to tackle these issues [5][7].

When the gaps are being closed and work is being performed as required, the "First hump" is about to be crossed. As the organization progresses in this mode, the systems become embedded in the culture of the organization. This is the stage of being "Consciously Competent (CC)", comparable to level 3, Control [7]. Success shall be achieved but individuals must be cognisant of what they are doing. They need to continue working very hard to follow the requirements of the system. During this period, the processes and procedures become embedded in the system, since all personnel involved need to keep working on all of the improvement systems which are successful and improving on the ones which are not. In this process, the effort required to achieve the organisational output shall reduce to levels lower than were existing previously. When the work culture has now changed so that the improved method of performing work is embedded in the system the stage of being" Unconsciously Competent(UC)" would have been reached, comparable to level 4 (Quality) and level 5 (Excellence) [7].

In this state, this superior method of performing work becomes automatic in the system, since the cultural change would have taken place. Superior Training, Competence and Discipline shall now be the main features in the organization. The quality requirements for the maintenance, repairs and operation of the equipment must be identified and documented so that there is repeatability and thus sustainability in the system.

The next set of changes in the system shall now start with the first of the technological "humps". This is the point when the first of the next level of improved technical initiatives are introduced so that they can be easily embraced and accomplished. The strategies necessary to cross this next 
hump and every other hump in the future, shall be similar to that required to cross the first hump, but with much less effort, since the workforce and the supporting systems shall be getting better at this exercise. The keys to success are discipline, being focused and sustainability. Model 1 and Model 2 identify the strategies necessary for the characteristic changes of the Reliability and Maintenance system and the embedding of the improvement initiatives into the system to achieve the sustainability required to set the platform for any further improvements.

\subsection{The Reliability Improvement (Model 3)}

Model 3 utilizes the theories from RCM and Failure Analysis [4], TPM [6], CMMS [7] and Planning and Scheduling [5] to provide the guidelines for the improvement strategy and Model 4 shall be used to provide the guidelines with respect to the functional trend of equipment. In all of these systems Planning and Scheduling of all work and the recording of all information derived, in the CMMS, are critical to success [5][7].

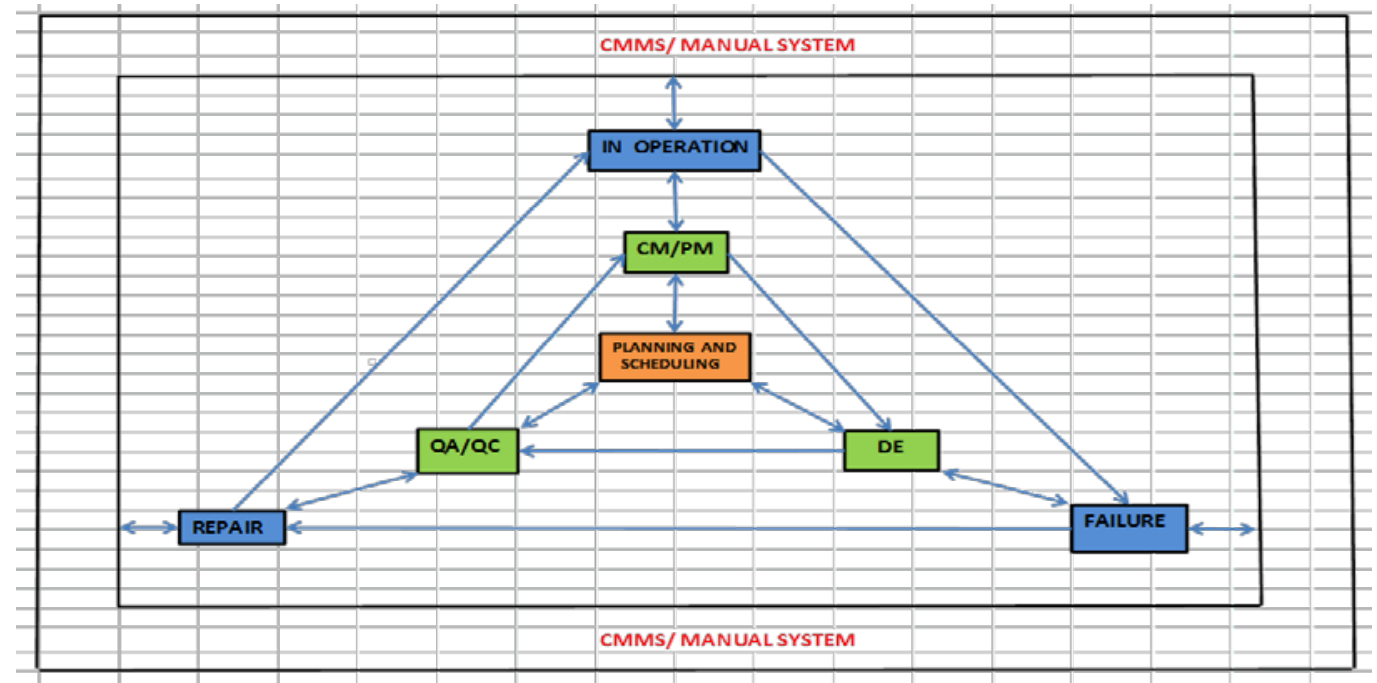

Figure 3. The Reliability Improvement Model 3 (Source: Jhagroo 2014)

When the equipment is in operation, the Condition Monitoring/Preventive Maintenance requirements must be identified using the OEM specifications and the improvements from past experience, all of which must be recorded in the CMMS under the unique history of each equipment. Model 4 as shown in Fig. 4, the modified P-F curve shall be used to assist in this respect.

Model 4 utilizes the theories of RCM [4] and identifies all of the stages in the functionality of equipment. When all equipment are installed they operate at their upper limit of functionality. During operation all equipment deteriorate at levels based on their design and robustness. At point "P”, potential for failure, the rate of deterioration increases indicating that failure is imminent and can occur at point "F". Failures due to infant mortality can occur before point "P". It must be noted that equipment can still function after point "F". At point "R1", some minor work is required to get the equipment to an operating point between the upper and lower limits of functionality. However if the equipment is allowed to operate beyond point " $\mathrm{R} 1$ ", then it can fail catastrophically and major work is necessary for repairs. 
To be in control and to impress a proactive approach to reliability in the system, the Reliability and Maintenance Engineers must ensure that the equipment is safely taken out of service before point " $F$ " is reached. At this point, the requisite Defect Elimination Analyses (e.g., Root Cause Analysis. 5-why's, and Ishikawa diagrams, FMECA etc..) must be completed to determine the root causes of failure and the recommendations developed, which shall then inform the Quality Assurance/Quality Control (QA/QC) systems for the repairs, installation and operation of the equipment.

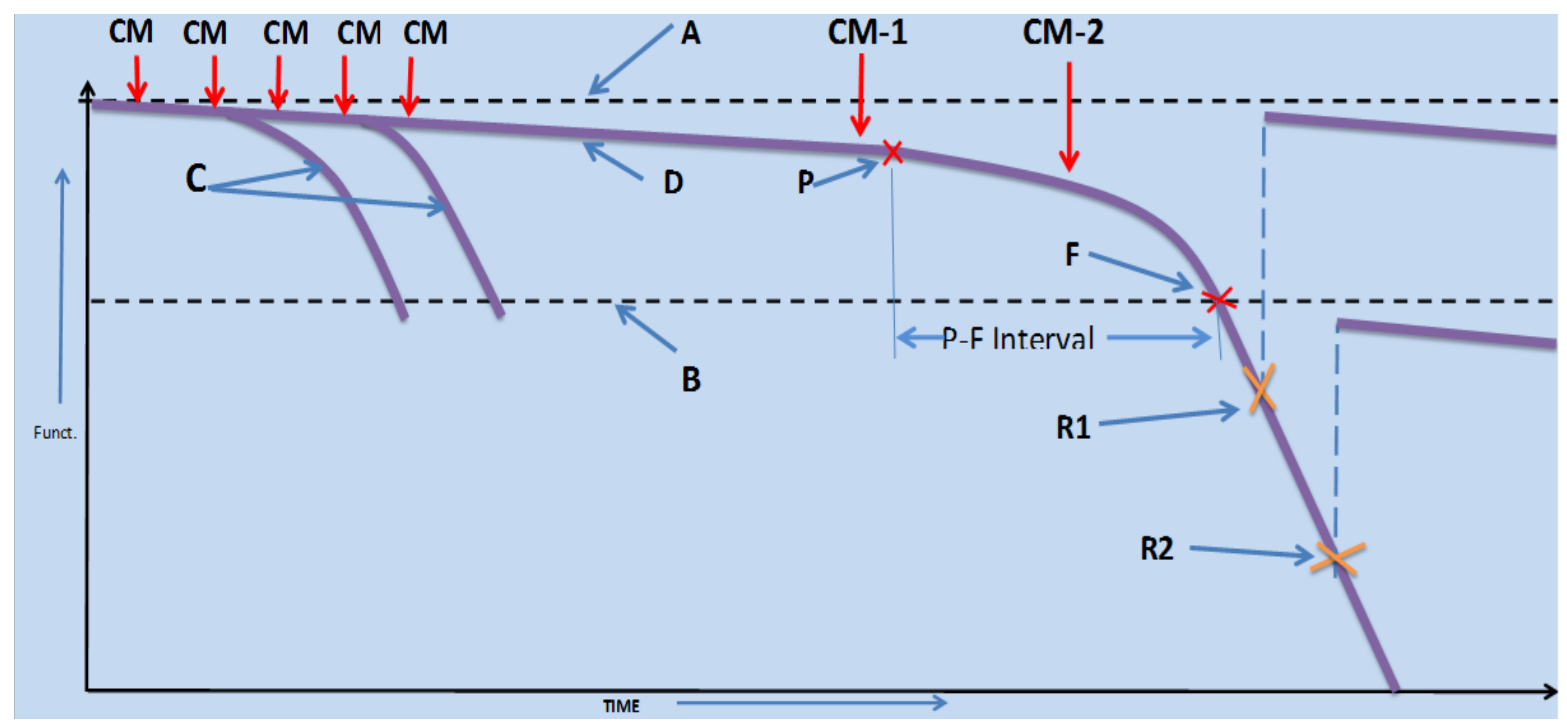

Figure 4. The Modified P-F Curve Model 4

Source: K. Jhagroo (2014) and extracts from the P-F curve-RCM-Moubry (1997)

The Reliability and Maintenance engineers shall audit these recommendations to ensure full compliance in the implementation. Again, these activities must be recorded in the CMMS under the unique equipment identification numbers and shall be optimally planned and scheduled to be effective [5].

\subsection{The CMMS (Model 5)}

Model 5 (Fig. 5) demonstrates the use of the CMMS to capture and utilise the information necessary for the repairs to a rotating equipment such as a pump or steam turbine. In this model one can see that at all stages of the repair, information is recorded in the CMMS. When the repair request is made in the field, all of the existing field information on the equipment functionality and failure is entered in the CMMS. When the equipment arrives in the repair shop, the field information is extracted from the CMMS and investigated. The required repairs are then completed and all of the relevant information is again placed in the CMMS. When the equipment is re-routed 
to the field, the information from the CMMS is extracted by field personnel so that they are aware of the type of repairs which were completed as well as any specific field requirements which are necessary to safely place the equipment in service.

All field installation information shall then be placed in the CMMS. The equipment shall now be placed in service and all of the information relative to this exercise shall be placed in the CMMS. If the equipment runs well and is accepted for operation, all work is closed off on the CMMS so that the final history information can be created for this repair. If however the placement in service was unsuccessful then a repeated request for repairs shall be created in the CMMS. At this stage all of the information collated in the CMMS for the equipment, up to this point, must be investigated to allow for any further repairs. Success in all Maintenance and Reliability functions are heavily based on a robust Planning and Scheduling system [5].

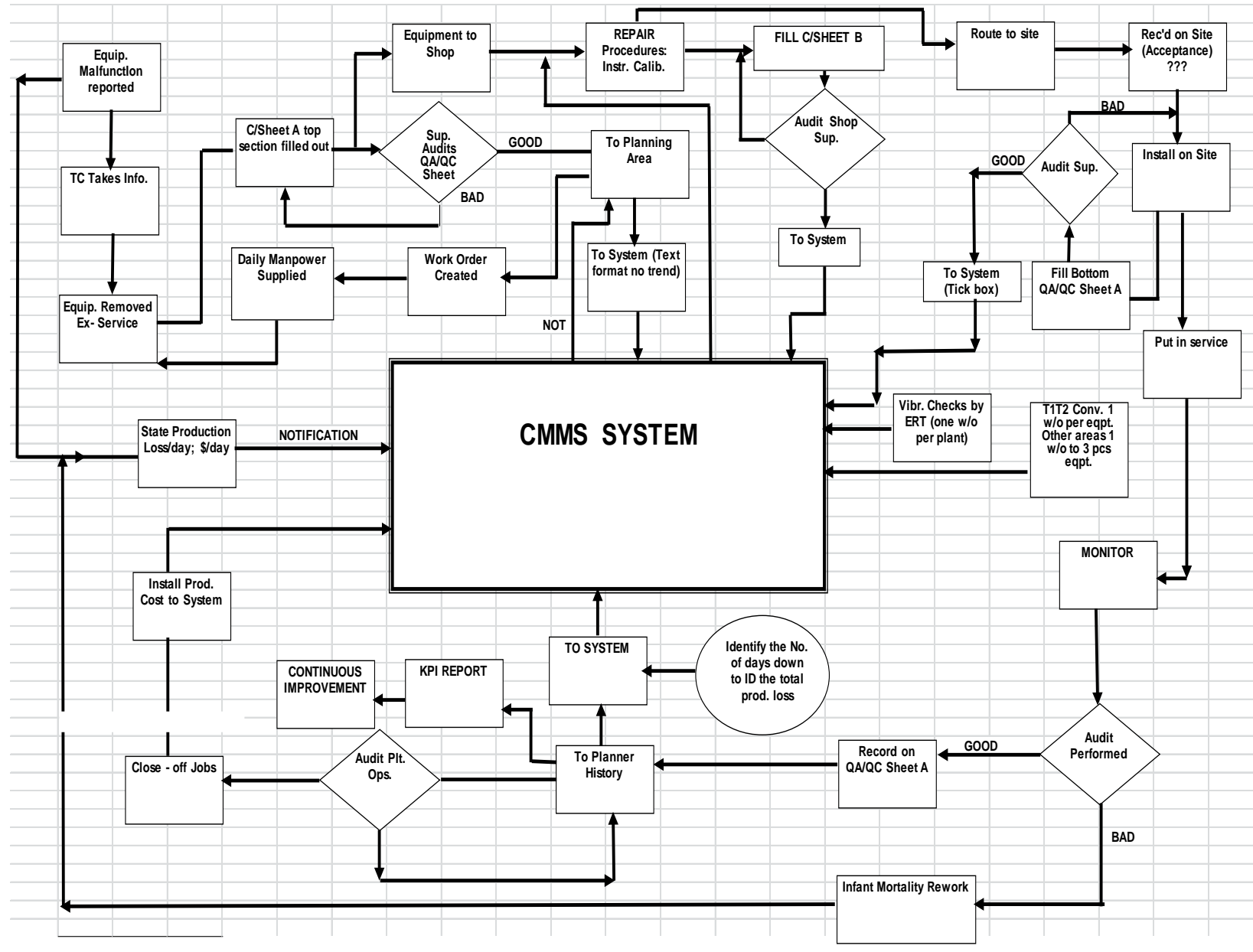

Figure 5. Model 5-The CMMS Repair Strategy Model (Source: Jhagroo, 2014)

\section{The KPI Tree (Table 1, Table 2 and the Strategy for Improvement)}

Key Performance Indicators (KPI's) need to be developed for all of the areas identified in the characteristic change and in the benchmarking processes. Authorised benchmarking consultants 
such as HSB Solomon and Associates, ISO Benchmarking Association (ISOBA), the Asset Management Information Service (AIMS) by MCP Management Consultants (the facilitators), need to be consulted for the specific type of industry concerned. These consultants already have KPI's which they use when studying an industry.

To ensure that an industry aligns itself with the benchmarking requirements, they need to use, as a minimum, the KPI's from these consultants so that there can be alignment during any benchmarking study. The most strategic lagging KPI's such as Mechanical Availability, Maintenance Costs and the Cost of Loss of Business, due to equipment issues, shall be placed at the top of the "KPI Tree”. These are the KPI's which shall be the focus of the senior management team, since this need to be in alignment with the Industry's strategic plan. This shall set the target values for the KPI's. These lagging KPI's shall then be broken down into the leading KPI's. The aim for the management team is to review the Lagging KPI's in great detail. For all attained or surpassed targets in the lagging KPI's, senior management needs to determine what is being performed well, by viewing the leading KPI's, and thus inject all learning derived, laterally into the system. For all areas not meeting the targets, the areas of required improvements need to be investigated by viewing the deficient leading KPI's and determining the root causes of the deficiencies. All recommendations derived must be implemented in a timely manner.

The aim is to have the trends in the lagging KPI's as the key performance indicators supported at the lower levels with the leading KPI's. On an overall basis all of these KPI's shall be used to trend the performance of the various types of equipment in the industry. All results must be displayed to all stakeholders, in a simple format such as graphs, and pie-charts etc., so that the workforce at all levels can see and understand what is going on. Ideas must be generated with their input as to how improvements can be achieved. This idea shall be hinged on one of the 8 pillars of TPM namely, Autonomous Maintenance [6]. This strategy motivates each stakeholder to become an agent of change in the improvement process. Samples of KPI records and check sheets are depicted in Tables 1 and 2. A typical KPI exercise would address the performance requirements as follows:

- Key Lagging KPI’s [7],

- Key leading KPI’s [7],

- Performance trends e.g., Mean Time between Maintenance (MTBM) for pumps, turbines, compressors, motors, instrument analysers, and boilers [1],

- Compliance reports on Condition Monitoring (CM) and Preventive Maintenance (PM) activities performed on specific types of equipment with priority settings [2],

- Compliance report on Failure Analyses being performed and on the recommendations made and completed with priority settings [5],

- Compliance reports on Inspection activities performed, recommendations made and completed with priority settings [5],

- Compliance reports on the Planning and Scheduling activities [5], and compliance reports on the QA/QC activities [7],

- Maintenance and Reliability Cost reports [3][5], and

- Compliance reports on the CMMS [5]. 
Table 1. KPI Record and Check Sheet (part \#1)

\begin{tabular}{|l|l|l|l|}
\hline KPI & ACTUAL & TARGET & $\begin{array}{c}\text { Actual vs. Target } \\
\%\end{array}$ \\
\hline Maintenance cost & & & \\
\hline Mech. Availability YTD & & & \\
\hline Cost of Business Loss & & & \\
\hline MTBM - Pumps (YTD) & & & \\
\hline MTBM - Heat Exchangers (YTD) & & & \\
\hline MTBF-Analyzers (YTD) & & & \\
\hline MTBF - Motors (YTD) & & & \\
\hline MTBM - Recip.Compressors (YTD) & & & \\
\hline $\begin{array}{l}\text { DE STATUS: } \\
\text {-Approved } \\
\text {-Awaiting Approval } \\
\text {-In Progress } \\
\text {-To be started }\end{array}$ & & & \\
\hline
\end{tabular}

Source: Jhagroo (2014)

Table 2. KPI Record and Check Sheet (part \#2)

\begin{tabular}{|c|c|c|c|}
\hline KPI & ACTUAL & TARGET & $\begin{array}{c}\text { Actual vs Target } \\
\%\end{array}$ \\
\hline $\begin{array}{r}\text { DE Recomm.- Existing } \\
\text {-Completed }\end{array}$ & & & \\
\hline $\begin{array}{r}\text { Mechanical PM/CM- Required } \\
- \text {-Completed }\end{array}$ & & & \\
\hline $\begin{array}{r}\text { Electrical PM/CMI- Required } \\
\text {-Completed } \\
\end{array}$ & & & \\
\hline $\begin{array}{r}\text { Instrument PM/CM-Required } \\
- \text { Completed }\end{array}$ & & & \\
\hline $\begin{array}{r}\text { Mech. Shop/site QA/QC -To be Done } \\
\text {-Completed } \\
\text {-In CMIMS }\end{array}$ & & & \\
\hline $\begin{array}{r}\text { Elect. Shop/site QA QC }- \text { To be Done } \\
- \text { Completed } \\
\text {-In CMIMS }\end{array}$ & & & \\
\hline $\begin{array}{r}\text { Instr. Shop/site QA/QC }- \text { To be Done } \\
\text {-Completed } \\
\text {-In CMrMS }\end{array}$ & & & \\
\hline
\end{tabular}

Source: Jhagroo (2014)

The senior Management team responsible for Maintenance and Reliability needs to meet with their key stakeholders in Maintenance and Reliability to discuss the KPI's and to determine methods for continuous improvement. The meeting must be chaired by the senior manager who is responsible for Asset Integrity at the level of the Board of Directors. The purpose of the meeting is to:

- Review the trends in the performance of equipment and the associated activities and discuss these when compared to specific targets based on the strategic plan. Differences to the targets, 
positive or negative, must be discussed so that all Learning and Deficiencies in the system can be identified.

- Develop the list of best performing equipment and the Learning derived from them-with the aim to inject these learning laterally into the system to allow for the improvement of the entire system. This must be accompanied with a Planning and Scheduling timeline.

- Develop the list of unacceptable performers and identify the "Bad Actor" equipment involved. Here the strategy for tackling this equipment shall be identified and the method for investigating the deficiencies decided on such as the Ishikawa Diagram, Five Why's, and Root Cause Analysis (RCA) FMECA etc. The system for the implementation of the recommendations from these exercises, with the requisite Planning and Scheduling timeline, shall be identified and the methods for auditing and sustaining the required compliance levels developed.

- The Senior Management team must be engaged for assistance in the event of any stumbling blocks in dealing with the learning and/or recommendations for improvement.

\section{The Strategic Process (Model 6) and the Alignment with the Strategic Plan}

The Senior Management Team needs to provide the guidance necessary for the lower levels of the organization to align the initiatives in Maintenance and Reliability with the strategic plan of the specific industry. The Maintenance and Reliability presentation to this Management Team is the main forum to discuss the elements of the strategic plan. This approach shall engage all stakeholders and shall set up a system of Autonomous Maintenance [6]. The performance needs to be trended over time. The designated Leader must always be ahead of the game and must take the lead in this change process in Maintenance and Reliability.

Model 6 identifies the stakeholders/areas impacted on by the elements of the strategic plan which are set at the level of the board of Directors of an industry. Middle management needs to take this strategic plan and convert it into implementable activities which can then be routed to the lower levels of the organization. Marketing meetings with the key stakeholders shall identify the production levels required by the industry. These future "horizons" shall be based on the Asset integrity level of the equipment.

A robust Maintenance and Reliability system shall allow for the confidence to set very long marketing "horizons". In order to support this Asset integrity, long term meetings must take place in each of the divisions/departments of the industry, where all of the work being performed in maintenance and reliability is discussed and trended. In this meeting the leading KPI's shall be discussed and the information recorded in an accurate and timely manner, in preparation for the presentation to senior Management. All work executed via the daily plans and schedules, must add value to the strategic plan. 


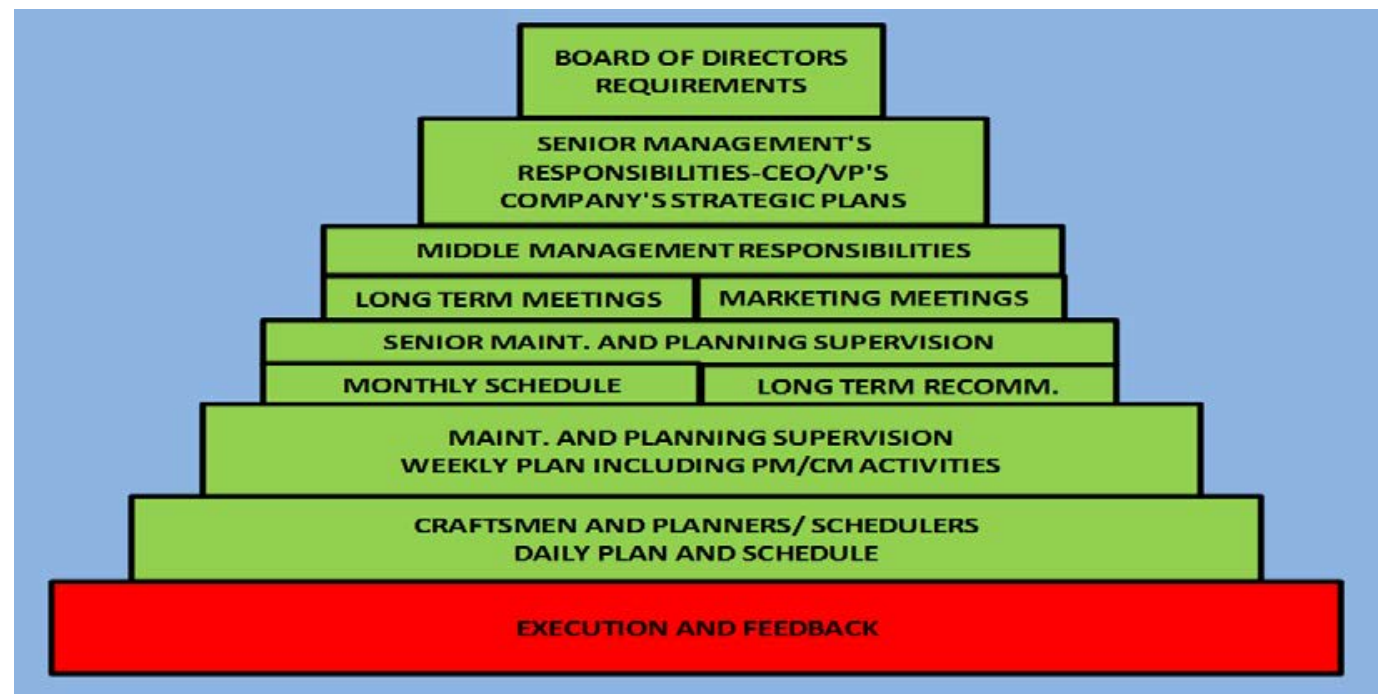

Figure 6. The Strategy Implementation Model 6 (Source: Jhagroo, 2014)

\section{Conclusion}

In conclusion there is no "silver Bullet" which shall allow any system to by-pass any of the humps identified in Model 1, especially the first "Physical" hump. There is a need to "sweat the system" to ensure that the process of crossing this Physical hump is attained so that the improvement process can be developed and embedded into the system. The strategies enumerated in the generic strategies of Reliability Centered Maintenance (RCM), Total Productive Maintenance (TPM), Kepner Tregoe problem solving (KT), Reddin’s 3D Leadership systems and Six sigma Black-belt system can be used to further fine tune many of the initiatives discussed.

The effort and time required to achieve the changes can in fact be very long and time consuming. Continuity can only be achieved with the use of an accurate and timely Planning and Scheduling system supported by an accurate CMMS [5]. The strategy must be started as part of the Industry's strategic plan set at the level of the Board of Directors with the required timelines developed at that senior level of the organisation. This initiative can only be driven from that level of management.

The various supporting strategies must then be outlined and systems developed by this top management team to drive them to completion. The various models can be used to manage the characteristic changes in the organisations and these can be supported by the KPI tree. The Maintenance and Reliability presentation to senior management is a key element to effectively and efficiently convert the strategic plan to the day-to-day execution activities by the workforce. The Planning and Scheduling system shall ensure timely execution of the initiatives, with the requisite feedback into the CMMS, which shall ensure sustainability and a method of continuous improvement.

The models provided can be used, to outline to all stakeholders the strategies necessary for a robust Maintenance and Reliability system. They simplify the concepts of the Maintenance and 
Reliability theories and therefore allow for a greater understanding of these concepts by these stakeholders who are not Engineers but on whom Engineers depend, to get the work performed to the quality levels required. The key to success is a synergistic working relationship between the Engineers and the stakeholders who have their hands directly on the jobs.

\section{References}

[1] Abernethy, R.B. (1994), The New Weibull Handbook, Gulf Publishing Company, Florida. [2] Herbaty, F. (1990), Training Handbook of Maintenance Management, 2nd edition, Noyes Publication, New Jersey

[3] Jardine, A.K.S. and Tsang, A.H.C. (2013), Maintenance Excellence: Maintenance Replacement and Reliability-Theory and Application, $2^{\text {nd }}$ edition, CRC group, Taylor and Francis Group, New York

[4] Moubry, J. (1997), Potential Failures and On-Condition Maintenance: Reliability-centered Maintenance, 2nd edition, Industrial Press Inc, New York.

[5] Palmer, D. (2013), Maintenance Planning and Scheduling Handbook, 3rd edition, Mc Graw Hill, New York

[6] Suzuki, T. (1994), TPM in Process Industries, Productivity Press, Portland Oregon

[7] Wilson, A. (2002) Asset Maintenance Management: A Guide to Developing Strategy and Improving Performance, Industrial Press Inc. New York.

\section{Author's Biographical Notes:}

Kishore Jhagroo is the Senior Lecturer and Coordinator of the MSc Engineering Asset Management Programme in the Department of Mechanical and Manufacturing Engineering, at The University of the West Indies West Indies (UWI). Before joining UWI, he worked as a Mechanical Engineer in the Crude Oil Refining Industry in Trinidad for 37 years. Mr. Jhagroo has a BSc (first class honours) in Mechanical Engineering and an MSc in Engineering Management, both from UWI. He is also a Certified Reliability Engineer (ASQ) and a certified Instructor with STLE. He has also obtained a certificate in the 6 Sigma Black-Belt programme. Mr. Jhagroo has presented papers, on Reliability and Maintenance on Plant Turnarounds, in Houston Texas, in Brazil, in Trinidad at the STLE Conferences and at the APETT's Annual Technical Conference in Trinidad and Tobago. His passion is the preparation of students in the MSc Engineering Asset Management and the other MSc Engineering programmes to synergistically fit into the Heavy and other Manufacturing Industries by being innovative, root cause and critical thinkers so that they can immediately add value to achieve the required Equipment Reliability and Availability in these industries. 